\title{
A review of energy saving techniques in mobile hydraulic machines
}

\author{
Sanjar Mirzaliev*
}

${ }^{*}$ Corresponding author.

Politecnico di Torino, Italy

E-mail: s254169@studenti.polito.it

\begin{abstract}
A fluid power industry powering the agricultural machinery faces big challenges nowadays. An issue of energy saving has become important due to increasing fuel costs and more stringent emissions regulations impacting vehicle development. A recent study conducted by the U.S. Department of Energy shows that the efficiency of fluid power averages 21 percent. This offers a huge opportunity to improve the current state-of-the-art of fluid power machines, in particular to improve the energy consumption of current applications and create innovative solutions. To increase energy efficiency of fluid power systems reduction of throttling losses and potential energy recovery strategies are needed.
\end{abstract}

Aim of this work is to present classification of current energy saving architectures and aid the development of new techniques for mobile fluid power machines.

Keywords: agricultural machinery; load sensing; independent metering; digital flow control; displacement control; constant pressure systems. 


\section{Introduction}

In fluid power, there exist many techniques to reduce/recover energy losses of the conventional layouts, e.g. load sensing, electrohydraulic flow matching, independent metering, etc. One of the most efficient ways to analyze these different layouts and identify the best hydraulic solution is done through virtual simulations instead of prototyping, since the latter involves higher investment costs to deliver the product into the market. However, to build a fluid power machine virtual model, some problems arise relative to different aspects, for instance: loads on actuators (both linear and rotational) are not constant and pumps are driven by a real engine whose speed depends on required torque. Furthermore, it is important to achieve higher level of detail to simulate each component in the circuit: the greater detail, the better the machine behavior is portrayed, but it obviously entails heavy impact on simulation time and computational resources. Therefore, there is a need to create mathematical model of components and systems with sufficient level of detail to easily acquire all those phenomena necessary to correctly evaluate machine performance and make modifications to the fluid power component design.

\section{Layout classification}

In general, mobile machines have multiple actuators and the operator's task is to regulate the speed of each actuator and drive. A typical example is the mobile excavator having Internal Combustion Engine (ICE), power of which generates the fluid power to propel swing, boom, arm and bucket cylinders.

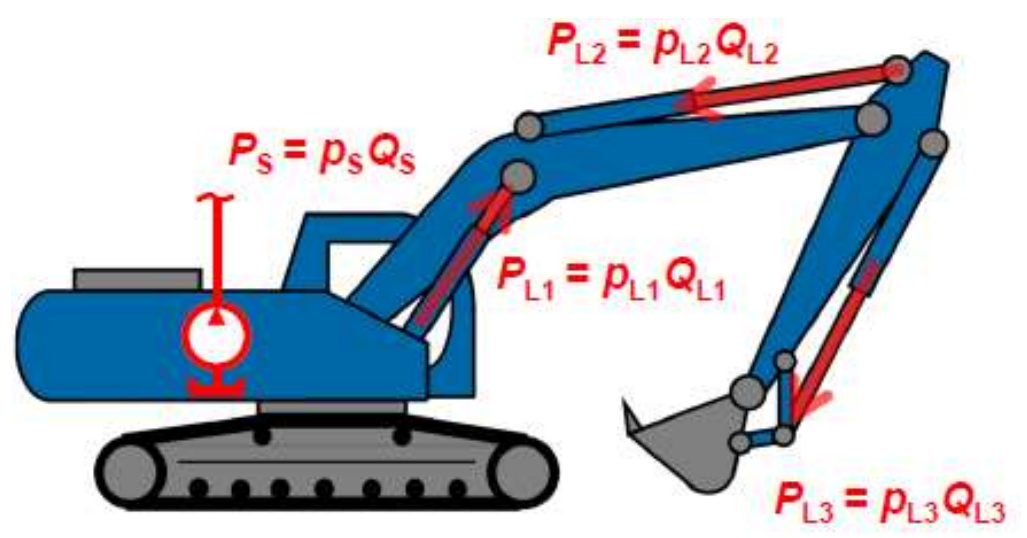

Figure 1 Mobile excavator with indication of powers

Energy consumption for a hydraulic system is defined as:

$$
E=\int_{t_{0}}^{t_{1}} p_{s} Q_{s} d t=\int_{t_{0}}^{t_{1}}\left(p_{L S}+s\right) \cdot\left(Q_{L}+Q_{C}\right) d t
$$


where $E$ represents the hydraulic energy used for a certain task from $\mathrm{t}_{0}$ to $\mathrm{t}_{1} ; \mathrm{p}_{\mathrm{s}}, \mathrm{p}_{\mathrm{LS}}$, and $s$ are the hydraulic supply pressure, load pressure and pressure loss respectively; $Q_{s}, Q_{L}$, and $Q_{c}$ are the flow rates of the pump, load and other flow rate such as leakage respectively. Reducing the energy consumption is equivalent to reducing the power, the integrand $\mathrm{p}_{\mathrm{s}} \cdot \mathrm{Q}_{\mathrm{s}}$. It is obvious that there are the following two ways to save energy [1]: (1) reduce the supply pressure, which can be realized by the decrease of pressure loss in valves; (2) reduce the pump flow rate, which can be realized by the flow regeneration with a differential hydraulic circuit.

In overall, to increase the energy efficiency of the mobile machine is to decrease throttling losses, avoid inefficient operating points and recover potential energy. In hydraulic system architectures, there are three layouts: supply concept, control concept and supply/control concept [2].

\begin{tabular}{|l|c|c|}
\hline \multirow{3}{*}{ Supply concept (S) } & flow (Q) & variable flow rate \\
\cline { 2 - 3 } & & constant flow rate \\
\cline { 2 - 3 } & pressure (P) & variable flow rate \\
\cline { 2 - 3 } Control concept (C) & \multirow{2}{*}{ primary control } & with flow supply concept \\
\cline { 2 - 3 } & \multirow{2}{*}{ conductive control } & with pressure supply concept \\
\cline { 2 - 3 } & & with flow supply concept \\
\cline { 2 - 3 } & actuator control & with flow supply concept \\
\cline { 2 - 2 } & & with pressure supply concept \\
\hline
\end{tabular}

In supply concept, actuator speed is accomplished via supply of flow rate or pressure. A figure below describes it in detail. $1 \mathrm{a}$ and $1 \mathrm{~b}$ are typical layouts of flow rate supply, whereas $2 \mathrm{a}$ and $2 \mathrm{~b}$ depict the system with pressure supply.

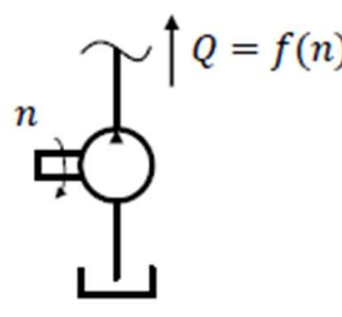

$1 a$

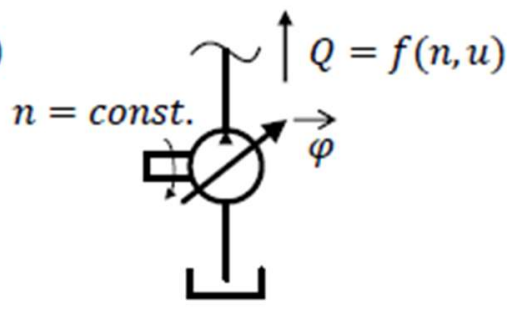

$1 b$

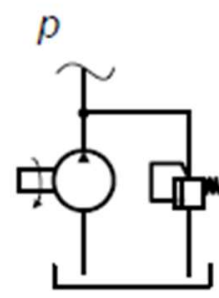

$2 a$

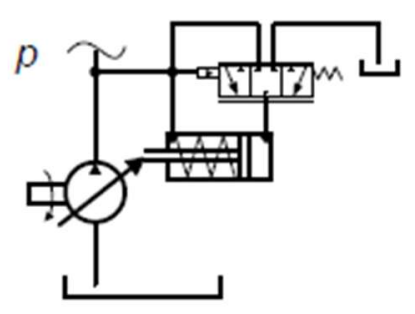

$2 b$

Figure 2 Supply concept examples

Supply concept examples. $1 \mathrm{a}$ and $1 \mathrm{~b}$ are flow supply, $2 \mathrm{a}$ and $2 \mathrm{~b}$ are pressure supply. 
In control concepts, there exist three types: Primary control (PC), Conductive Control (CC) and Secondary Control (SC). Primary control is accomplished by means of controlling prime mover, e.g. variable displacement pump. In Conductive Control instead, power is adjusted via control valves, such as proportional distributor. Finally, in the Secondary control, linear or rotational speed is adjusted with the help of actuators themselves, for example, variable displacement motor. A figure below classifies each of the three control concepts.

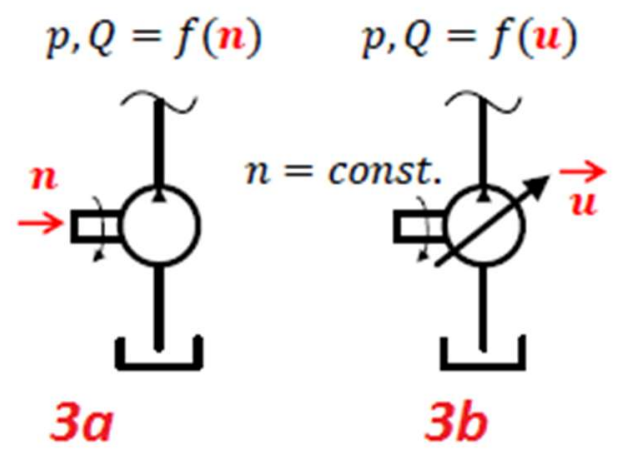

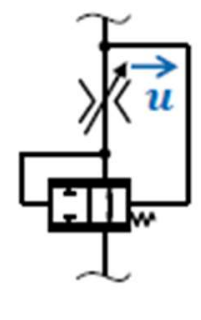

$4 a$

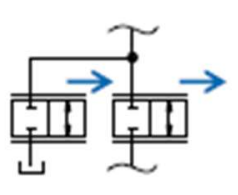

$4 b$

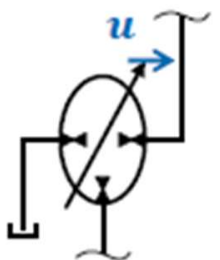

$4 c$

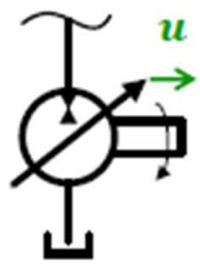

5

Figure 3 Control concept examples: primary, conductive and secondary

$3 a$ and $3 b$ are typical examples of primary control concept with fixed displacement pump or variable displacement pump respectively. $4 \mathrm{a}, 4 \mathrm{~b}, 4 \mathrm{c}$ - examples of conductive control strategy. In 3 , there is pressure control valve upstream of the metering edge, diameter of which is controlled by the operator mechanically or electronically. In 4 , an illustration of independent metering system is given. 5 is the example of hybrid transformer. 5 - an example of secondary control concept, where in pressure-imposed setup, motor displacement defines available torque and the flow rate is the function of the load.

In Supply/Control concept, where both concepts come together in the fluid power architecture, make a matrix as in the following. 


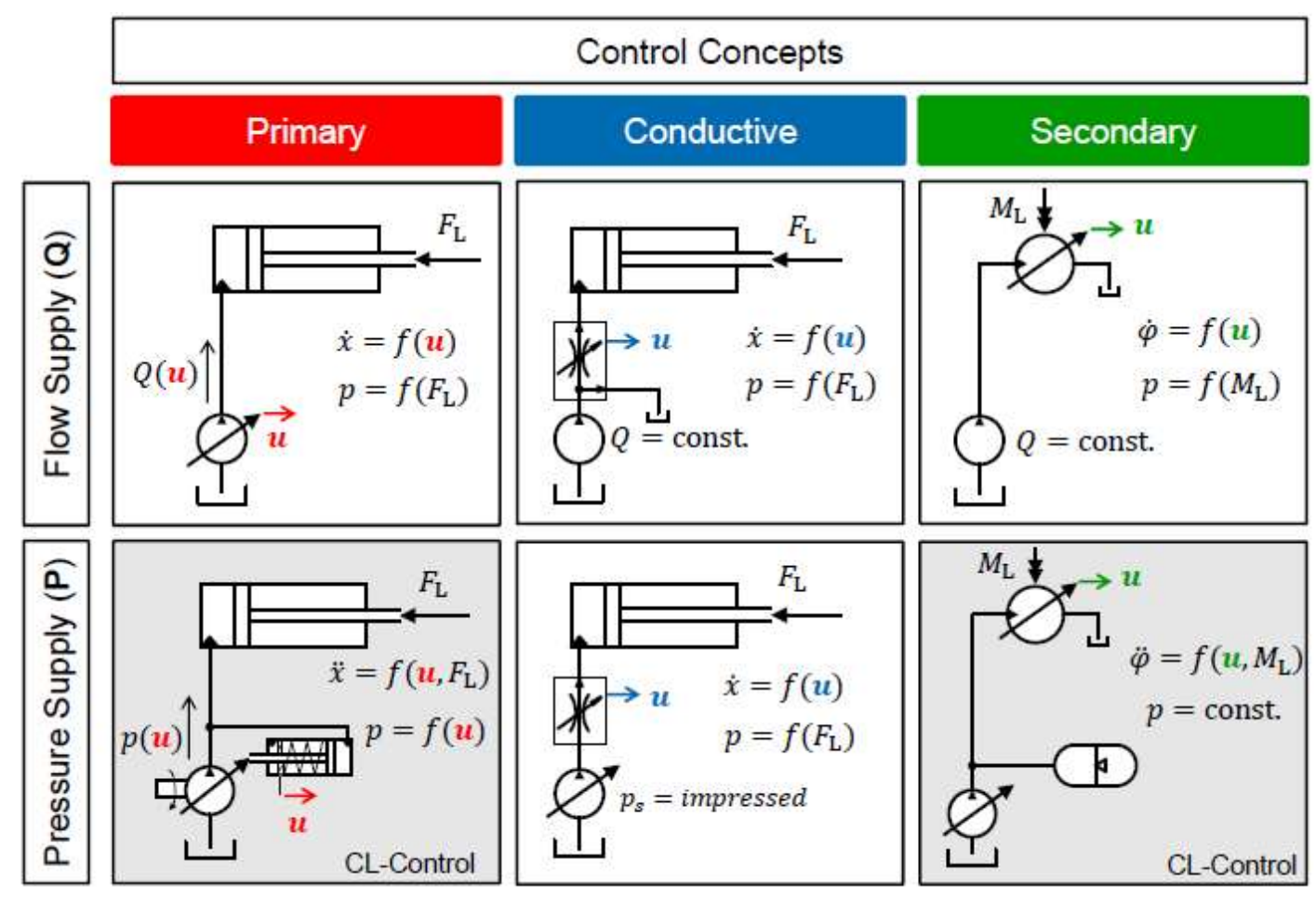

Figure 4 Matrix of energy saving architectures referenced in [2]

\section{Energy saving architectures}

Nowadays, Load Sensing technique is current as an industry standard, where pump flow is matched follow the flow demands of all actuators. Pump pressure is set to "sense" the highest load pressure present in the circuit via pilot lines. For the sake of simplicity, a typical example of Load Sensing technique is explained in figure below [3].

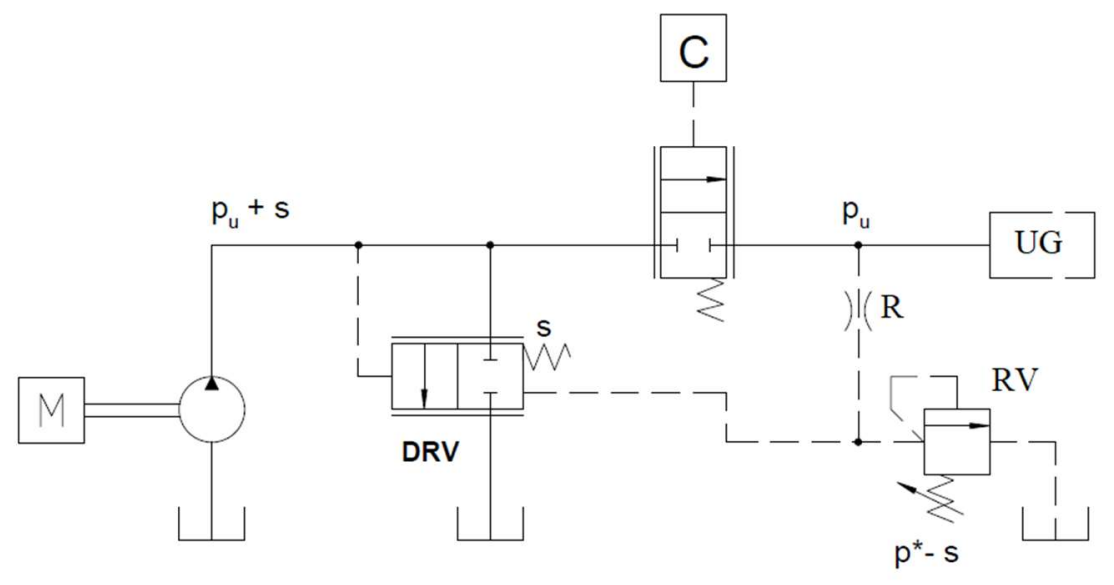

Figure 5 Load sensing plant with constant displacement pump [3] 
In this case the pressure at the pump outlet follows the pressure at the user group. Therefore, the pump works at pressure $p_{u}+s$. Power is calculated as

$$
\begin{aligned}
& P_{\text {exp }}=Q_{0} \cdot\left(p_{u}+s\right) \\
& P_{w}=Q_{s} \cdot s+\left(Q_{0}-Q_{u}\right) \cdot\left(p_{u}+s\right)
\end{aligned}
$$

There is also a better yet expensive solution as in figure below. By using the pump with differential pressure limiter, the flow rate wasted in DRV is not generated.

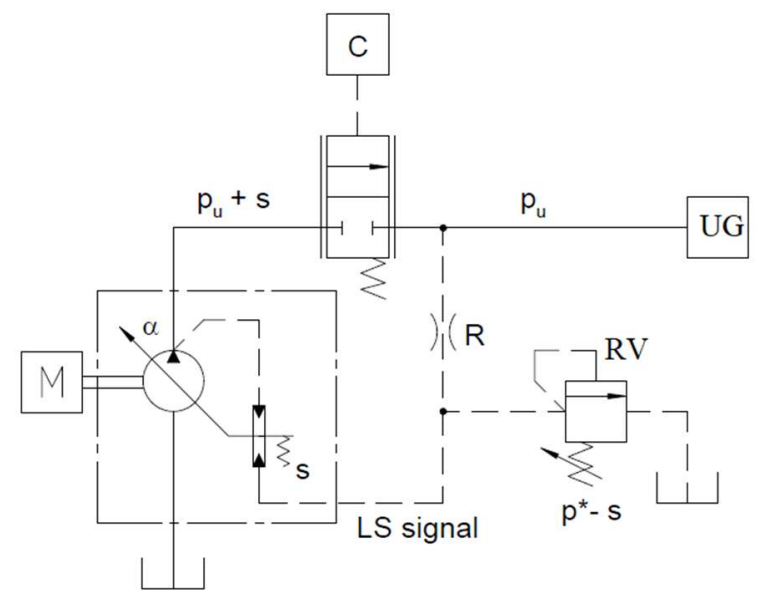

Figure 6 Configuration with differential pressure variable displacement pump [3]

A lot of material has been published throughout the years, explaining the basic working principles of LS-systems and the benefits and drawbacks they introduce as compared to traditional constant pressure systems, see e.g. [4-8], including minor modifications that may be made, see e.g. [9-12]. When it comes to the understanding of the dynamic behavior of a LSsystem, the saturation problems were addressed in [13], where the reasons for and the effects of both pressure and flow saturation was described. The reasons for instability in a LS-system are referenced in [14-18].

Independent metering reduces throttling losses and pump flow can be reduced because energy regeneration is possible. High responsive valves and control is needed to deliver this solution to the market.
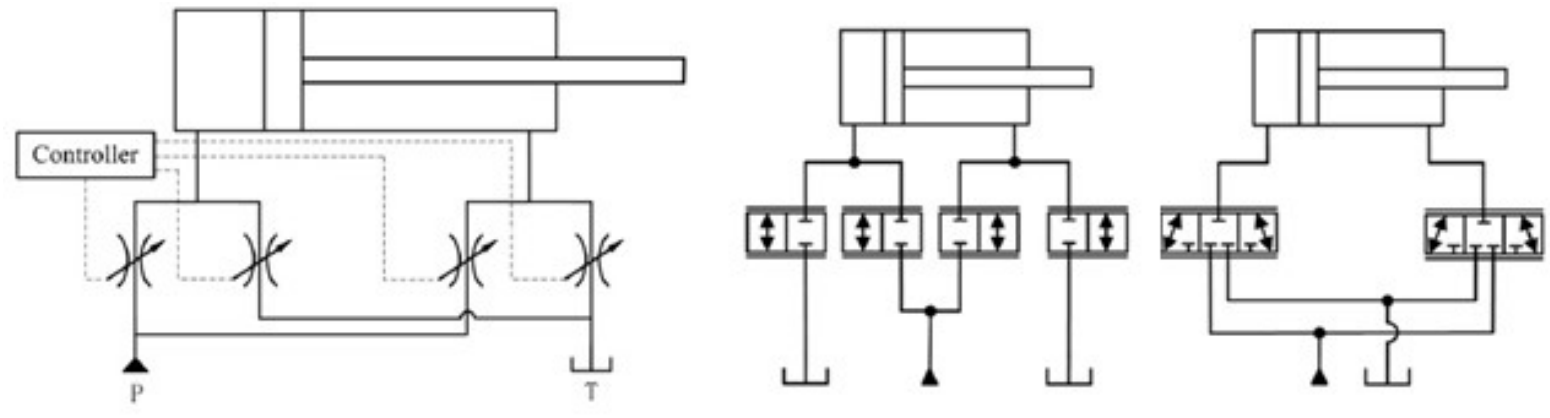

Figure 7 Possible layouts of independent metering 
Many researchers highlighted the independent control strategies of flow and pressure [19-30].

Digital flow control is made with analog supply concept with digital control concept. Simple on/off valves with affordable high response. In other literature, it is also known as flow matching. A challenge of this layout is to smoothen pressure peaks and obtain smooth motion control. Linjama [31] is a good references of digital flow control.

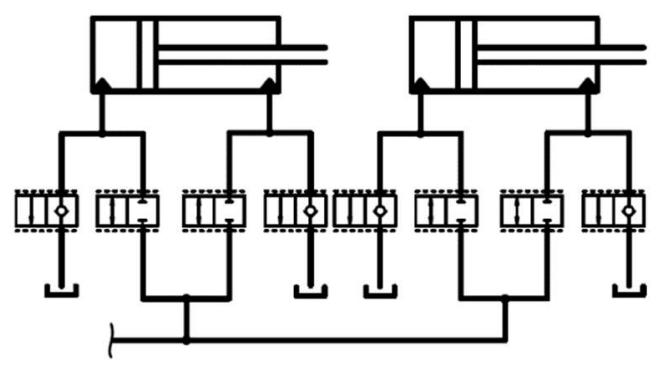

Figure 8 Digital flow control ISO scheme

Other energy efficient alternatives to LS-systems are pump controlled drives [32], where one dedicated pump is used for controlling each actuator. Actuator speed is controlled by displacement control of the pump. Until now this solution has not been used commercially, due to the high cost of variable displacement pumps and the lower dynamic performance as compared to valvecontrolled drives. With the advances of digital displacement pumps, as the Artemis [33], this may however change in the future. This layout has no inherent throttling losses. Pump displacement is designed for peak flows. Energy regeneration is possible as well. Displacement Control coupled with independent metering allow pump flow reduction. Open loop pump displacement control with independent metering, as in figure below, is the combination of flow supply concept and control concept at the same time. It has great potential to reduce pump flow, since Wheatstone bridge valves are used for flow regeneration.

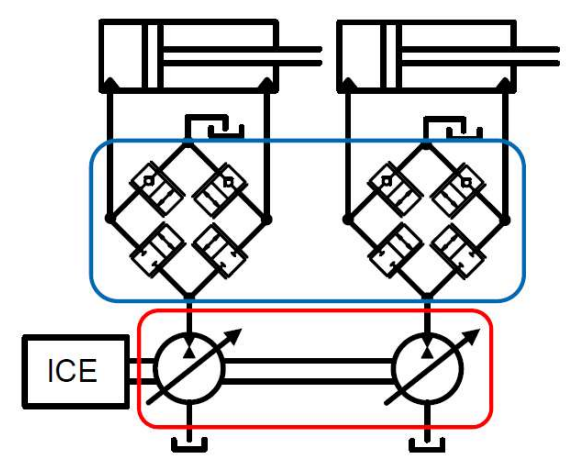

Figure 9 Displacement control with independent metering

Constant pressure systems allow avoiding throttling losses caused by the control principle. For example, ICE runs the pump, which in turn supplies High-Pressure and Low-Pressure supply lines. Hydraulic Transformers are installed between supply lines and actuators, which allow 
smooth transient conditions. Analogue and digital valves can be used to accomplish flow regeneration and recuperation.

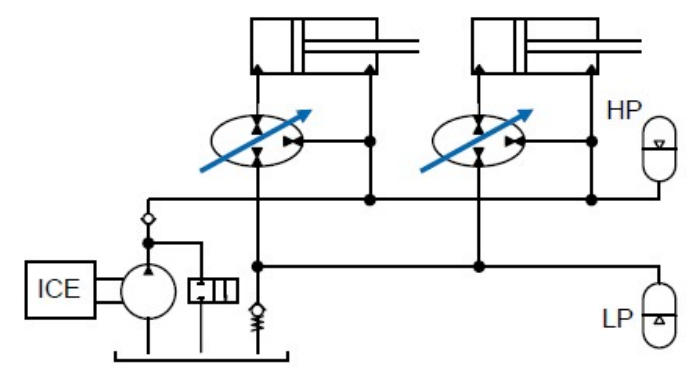

Figure 10 Constant pressure system with hydraulic transformers

\section{Conclusions}

In this paper the current state of fluid power architectures is discussed. Nowadays both analog and digital supply concepts are actual. The current trend in control concept of hydraulic circuits is to use more digital control concept. It is also possible to classify supply/control concept, where combination of primary, conductive and secondary controls can come together. Energy recovery is implied by using recuperation and regeneration techniques.

Furthermore, load sensing systems is described as the current industry standard. Several alternative system types have been presented, such as independent metering, digital flow control, displacement control and constant pressure systems. There is still research in those new areas that needs to be studied before the systems will reach their optimal condition.

\section{Notations}

$\begin{array}{ll}U G & \text { user group } \\ R V & \text { relief valve } \\ R & \text { restrictor } \\ D R V & \text { directional relief valve } \\ M & \text { motor } \\ P_{\text {exp }} & \text { expended power } \\ P_{w} & \text { wasted power } \\ Q_{0} & \text { flow rate generated by the pump } \\ Q_{u} & \text { flow rate received by the user } \\ p_{u} & \text { pressure drop across proportional direction control valve } \\ S & \text { cracking pressure of proportional directional control valve } \\ P_{u} & \text { useful power }\end{array}$




$\begin{array}{ll}P_{\text {exp }} & \text { expended power } \\ C & \text { control signal } \\ \alpha & \text { swash plate index } \\ u & \text { flow control parameter } \\ M_{L} & \text { load torque } \\ F_{L} & \text { load force } \\ \dot{\varphi} & \text { load speed } \\ \ddot{\varphi} & \text { load acceleration } \\ n & \text { rotary speed } \\ I C E & \text { internal combustion engine }\end{array}$

\section{References}

[1] - B. Yao, L. Song, Energy-saving control of hydraulic systems with novel programmable valves, The 4th World Congress on Intelligent Control and Automation, 4, IEEE

Press, Shanghai 2002, pp. 3219-3223.

[2] - Hubertus Murrenhoff - An Overview of Energy Saving Architectures for Mobile Applications, IFAS March 25,2014

[3] - Nervegna, N., Rundo, M.: Fluid power 2, Politeko, 2012, ISBN 978-88-97862-00-0.

[4] - B.R. Anderson. A survey of load sensing systems, BFPR Journal, no. 13, 1980.

[5] - H.W. Nikolaus. Loadsensing - lastunabhängige dosierung von verbraucherströmen.

Ölhydraulik und Pneumatik, 38(4), 1994.

[6] - R.N. Rathi. A load sensing hydraulic system as applies to hydraulic lift cranes. 31st

National Conference on Fluid Power, 1975.

[7] - G.K. Warren. Efficient and flexible hydraulic systems for mobile equipment. Proc. of the 7. Aachener Fluidtechnisches Kolloqium, 1986.

[8] - W. Backé. Hydraulic drives with high efficiency. Fluid Power Systems and

Technology (ASME), (2), p. 45-73, 1995.

[9] - K. Ichiryu. Recent trend and future forecast of hydraulic system and control of hydraulic excavator. Proc. of the 9. Aachener Fluidtechnisches Kolloquium, 1990.

[10] - J.P. Kipp. Load-sensing - zentralhydraulik für traktoren. Ölhydraulik und Pneumatik, No. 1, Jan. 1993.

[11] - W. Backé. Present and future of fluid power. Journal of Systems \& Control Engineering, Part I, 207(4), 1993.

[12] - A. Wolf and U. Maier. Load-sensing systeme in der erntechnik. Ölhydraulik und Pneumatik, 45(10), 2001.

[13] - L.G. Zarotti and N. Nervegna. Saturation problems in load-sensing architectures.

Proc. 43rd National Conference on Fluid Power, volume 43, 1988.

[14] P. Krus. On Load Sensing Fluid Power Systems, with Special Reference to Dynamic

Properties and Control Aspects. PhD thesis no. 183, Linköping University, Sweden, 1989.

[15] - P. Krus. Modelling and analysis of the dynamic properties of mobile hydraulic systems. Proc. 2nd Bath International FPWCS, 1989.

[16] - P. Krus and T. Persson. Dynamic properties of load sensing systems. Proc. of International Conference on Fluid Power, Tampere Finland, 1987.

[17] - S.D. Kim, H.S. Cho, and C.O. Lee. Stability analysis of a load-sensing hydraulic system. Proc. of the Institution of Mechanical Engineers, part A, 202(A2), 1988.

[18] - Y. Sakurai, K. Takahashi, and S. Ikeo. Study on the dynamics of a load sensing system. Proc. IMECE'96, ASME, 1996. 
[19] - M. Linjama, M. Huova, M. Vilenius, On stability and dynamic characteristics of hydraulic drives with distributed valves, in: D.N. Johnston (Ed.), Power transmission and motion control 2007, University of Bath, UK 2007, pp. 67-79.

[20] - M. Elfving, J.O. Palmberg, Distributed control of fluid power actuators-decoupled chamber pressure controlled cylinder, Proceedings of the 9th Bath International Fluid Power Workshop, Bath, UK, 1996.

[21] - M. Elfving, A concept for a distributed controller of fluid power actuators(Dissertation) College of Mechanical Engineering, Linköping University, Sweden, 1997.

[22] - B. Eriksson, J. Larsson, J.-O. Palmberg, Study on Individual Pressure Control in Energy Efficient Cylinder Drives, in: M. Ivantysynova (Ed.), 4th FPNI-phD Symposium, Sarasota, USA 2006, pp. 77-99.

[23] - B. Eriksson, M. Rosth, J.-O. Palmberg, Energy saving system utilizing LQ-technique design, in: Y.X. Lu, Q.F. Wang, et al., (Eds.),Proceedings of the 7th International Conference on Fluid power transmission and control, Hangzhou, China 2009, pp. 224-229.

[24] - Q. Yuan, J. Lew, Modelling and Control of Two Stage Twin Spool Servo-Valve for Energy-Saving, American Control Conference; Portland, USA, 2005.

[25] - B. Nielsen, Controller Development for a Separate Meter-In Separate Meter-Out Fluid Power Valve for Mobile Applications(Dissertation) Aalborg University, Denmark, 2005.

[26] - B. Yao, L. Song, Energy-saving control of hydraulic systems with novel programmable valves, The 4th World Congress on Intelligent Control and Automation, 4, IEEE

Press, Shanghai 2002, pp. 3219-3223.

[27] - L. Song, B. Yao, Coordinate control of energy saving programmable valves, IEEE Transactions on Control Systems Technology 16 (1) (2008) 34-45.

[28] - P. Opdenbosch, N. Sadegh, W.J. Book, Modeling and control of an electro-hydraulic poppet valve, Fluid Power Systems \& Technology Division-ASME 11 (2004)

$103-110$.

[29] - P. Opdenbosch, N. Sadegh, W.J. Book, Intelligent controls for electro-hydraulic poppet valves, Control Engineering Practice 21 (2013) 789-796.

[30] - A. Hansen, T. Andersen, H. Pedersen, L. Wachmann, Investigation of energy saving separatemeter-in separate meter-out control strategies, 12th Scandinavian International Conference on Fluid Power, SICFP '11, Tampere, Finland, 2011.

[31] - Linjama, Matti. "Is it time for digital hydraulics?." The proceedings of the 5th Scandinavian Int. Conf. on Fluid Power, SICFP'03, May 7-9, Tampere, Finland. 2003.

[32] - X. Liang. On Improving Energy Utilization in Hydraulic Booms. PhD thesis, Acta

Polytechnica Scandinavia: Mechanical Engineering Series, 2002.

[33] - Salter, Stephen H., and William HS Rampen. "Pump control method and poppet valve therefor." U.S.

Patent No. 5,190,446. 2 Mar. 1993. 